\title{
A case for integrating substance use harm reduction into IPAC practice in acute care settings
}

\author{
Christopher Wituik BScN, RN, $\mathrm{CIC}^{1}$ \\ ${ }^{1}$ Infection Prevention and Control \\ St. Joseph's Healthcare Hamilton, ON, Canada \\ cwituik@stjoes.ca
}

KEYWORDS:

Harm Reduction, Injection Drug Use, Infection Prevention \& Control, Acute Care, Health Equity

Harm reduction interventions for people who inject drugs (PWID) based in acute care hospitals have yet to be widely adopted or evaluated despite robust evidence from community settings supporting their impact on reducing injection drug-related harms, such as infections. [1,2] It is well known that injection drug use can lead to many infectious complications such as skin and soft tissue infections, bacteremia, infectious endocarditis, and transmission of various blood-borne pathogens such as HIV and hepatitis C. $[3,4]$ Once admitted to hospitals, PWID may not have access to harm reduction services offered in the community, which could increase their risk of infection. I argue that Infection Control Practitioners (ICPs) are well positioned and have the ethical imperative to advocate for and support the implementation and evaluation of harm reduction programs such as needle-syringe programs (NSPs), supervised consumption services, and harm reduction education within acute care hospital settings.

Once admitted to acute care settings, many PWID continue to inject drugs throughout their hospitalization and the commonly enacted abstinence-based models, which prohibit drug use and syringe possession lack effectiveness. [5,6] Without the integration of harm reduction services like NSPs into the acute care setting, the infectious risks associated with intravenous drug use persist in our institutions, and are left unmitigated by evidence-based interventions.

When PWID use substances in the hospital setting, it is often the result of inadequate pain control or management of withdrawal. [7] Without access to supportive, culturally safe environments and sterile supplies, individuals may take efforts to hide their use to avoid penalization. $[7,8]$ These efforts, such as rushed injection, injecting alone in locked washrooms, and using non-sterile syringes and supplies, could lead to various infections, overdose and death. [6,7] It is through a complex interplay of structural vulnerability and normalization of suffering that these risks may be framed as natural consequences of substance use. [7] When this suffering is seen as unavoidable and expected, healthcare providers and hospital leadership may be less likely to recognize opportunities where they can intervene.

To help mitigate these risks, ICPs can support the creation of comprehensive in-hospital harm reduction programs in line with their respective local context and epidemiology. This can be done through collaboration with key stakeholders such as PWID, nurses, infectious disease and addictions medicine specialists, psychiatrists, social workers, hospital leadership and local public health bodies. Common harm reduction interventions used in the community setting to curb the incidence of these infectious complications include: NSPs, supervised consumption services, distribution of biohazard sharps containers; distribution of safer injection kits, which may include alcohol swabs and sterile injection equipment; and educational materials.

While Infection Prevention and Control departments are comfortable working within the focused lens of their respective organizations, we need to also think broadly with a health equity lens to reduce systemic and socially constructed (and therefore modifiable) risks faced by PWID in the hospital setting. Turning a blind eye to the risk environment that is our hospitals perpetuates health disparities and is not an option. We need to think outside the box and leverage our knowledge of infectious processes and our skills in education and policy development to help reduce the harm experienced by PWID.

\section{REFERENCES:}

1. Sharma, M., Lamba, W., Cauderella, A., Guimond, T., \& Bayoumi, A. (2017). Harm reduction in hospitals. Harm Reduction Journal, 14(32), 1-4. doi:10.1186/s12954-017-0163-0.

2. Brooks, H., O'Brien, D., Salvalaggio, G., Dong, K., \& Hyshka, E. (2019). Uptake into a bedside needle and syringe program for acute care inpatients who inject drugs. Drug and Alcohol Review, 38(4), 423-427. doi:10.1111/dar.12930. 
3. Dahlman, D., Håkansson, A., Kral, A., Wenger, L., Ball, E., \& Novak, S. (2017). Behavioural characteristics and injection practices associated with skin and soft tissue infections among people who inject drugs: A community-based observational study. Substance Abuse, 38(1), 105-112. doi:10.1080/0889707 7.2016.1263592.

4. Gordon, R., \& Lowy, F. (2005). Bacterial infections in drug users. New England Journal of Medicine, 353(18), 1945-1954. doi:10.1056/NEJMra042823

5. Grewal, H., Ti, L., Hayashi, K., Dobrer, S., Wood, E., \& Kerr, T. (2015). Illicit drug use in acute care settings. Drug and Alcohol Review, 34(5), 499-502. doi:10.1111/dar.12270.

6. Barter, D., Johnston, H., Williams, S., Tsay, S., Vallabhaneni, S., \& Bamberg, W. (2019). Candida bloodstream infections among persons who inject drugs - Denver Mentropolitan Area,
Colorado, 2017-2018. Morbidity and Mortality Weekly Reports. 68(12), 285-288. doi:10.15585/mmwr.mm6812a3

7. McNeil, R., Small, W., Wood, E., \& Kerr, T. (2014). Hospitals as a risk environment: An ethno-epidemiological study of voluntary and involuntary discharge from hospital against medical advice among people who inject drugs. Social Science \& Medicine, 105, 59-66. doi:10.1016/j. socscimed.2014.01.010.

8. McNeil, R., Kerr, T., Pauly, B., Wood, E., \& Small, W. (2015). Advancing patient-centered care for structurally vulnerable drug-using populations: a qualitative study of the perspectives of people who use drugs regarding the potential integration of harm reduction interventions into hospitals. Addiction, 111(4), 685-694. doi:10.1111/add.13214 *

\section{CALL FOR PAPERS}

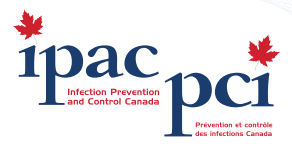

The Canadian Journal of Infection Control is a leading international peer-reviewed journal providing a platform for knowledge transfer and academic discourse in the field of infection prevention and control and hospital epidemiology. The journal invites submission of manuscripts outlining original research that examines, informs, and advances this professional field.

Authors should follow the content and format recommendations as outlined in the journal's Guidelines for Authors (https://ipac-canada.org/canadian-journal-of-infection-control-3.php). Manuscripts are accepted in English and French and should be submitted electronically by emailing all materials to the attention of:

Victoria Williams, Editor-in-Chief

Canadian Journal of Infection Control

editor-in-chief@ipac-canada.org

A signed copy of IPAC Canada's Publisher-Author agreement must be received before a manuscript will be published. The agreement is available at https://ipac-canada.org/canadian-journal-of-infection-control-3.php.

Please note that there is an approximate three- to four-month timeline between receipt of manuscript, peer review, editing, and publication. The Canadian Journal of Infection Control is a quarterly publication indexed by the Cumulative Index to Nursing and Allied Health Literature (CINAHL)/EBSCO, SilverPlatter Information, Inc. and CrossRef.

\section{Hand Sanitizing Perfection}

\footnotetext{
- The Original Hand Sanitizing Station

- Increases Efficacy of Your Hygiene Supplies

- Eliminates Flimsy Drip Catches

- Prevents Facility Damage

- Ergonomic \& Accessible Design

- Many Configurations \& Uses
}

Cleaning hands across Canada since 2005. Made in Canada. Built-to-order.

\section{tagg CLEANOHANDS ${ }^{\circledR}$ taggcleanhands.com \\ Draw Attention, Educate \& Dispense. \\ 416-249-2220}

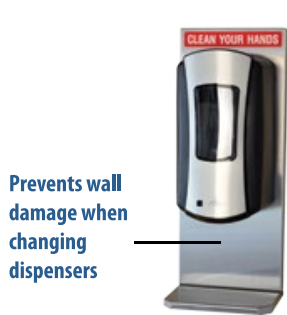

Single focus,

no ads

Updateable message areas

Mount your choice of

dispenser supplies

Long lasting

surgical-grade

stainless steel
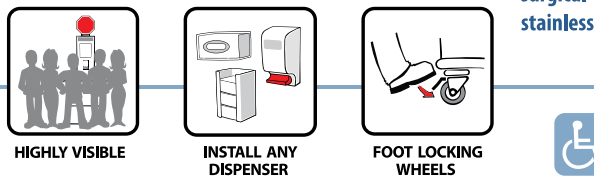

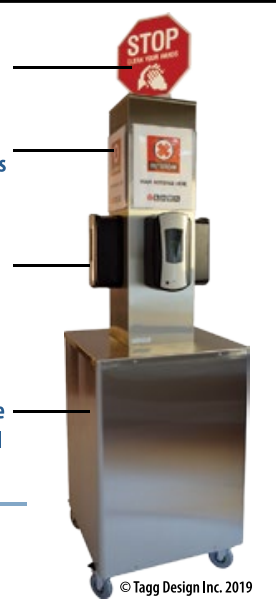

